\title{
Problems of HIV/AIDS infected women in Manipur: agenda for policy change
}

\author{
M. Romesh Singh \\ Visiting Scholar, Department of Anthropology, University of North Texas, Denton, USA \\ Department of Anthropology, University of Hyderabad, India
}

\begin{abstract}
Manipur has experienced an alarming rise in human immunodeficiency virus (HIV) infected persons and persons with acquired immune deficiency syndrome (AIDS), which has been the most serious public health problem, and AIDS has become the number one killer of young people. This tiny state is one of the top six states having the highest number of HIV-positive cases in the country. Initially, it was mainly spread through injecting drug users but now the epidemic is not only confined to the injecting drug users and has spread to their sexual partners, to their children, and to others as well. The majority of the infected people belong to younger and working age groups; it is reported that the HIV sero-prevalence rate among pregnant women has raised alarmingly. The impact of HIV is also more severely felt by the women in the state. In these families, women provide financial support to the family and they find it difficult to earn their livelihood due to the lack of availability of work in the state. In such situations they are forced to work as commercial sex workers. This has also increased the risk of infection among women who were previously considered as being a low-risk group. One should bear in mind that the risk of infection among women means the risk of infection for generations to come. In this backdrop, the present article is an attempt to explore the problems of HIV/AIDS infected women in Manipur.
\end{abstract}

HIV AIDS Rev 2017; 16: 5-10

DOI: https://doi.org/10.5114/hivar.2017.65198

Key words: gender, vulnerability, empowerment, discrimination, victimisation, infected.

\section{Introduction}

The human immunodeficiency virus/acquired immune deficiency syndrome (HIV/AIDS) epidemic represents a serious public health problem in society. It is currently spreading in the world at the rate of one new infection every fifty seconds. HIV/AIDS is not confined to any one class, community, religion, age group, sex, or profession although, according to the Indian Health Organisation (IHO), women and children are believed to be more prone to AIDS. Today, women have consistently constituted more than half of those infected with HIV globally. There are now 17 million women and 18.7 million men between the ages of 15 to 49 years living with HIV/

Address for correspondence: Dr. M. Romesh Singh, Department of Anthropology, University of Hyderabad, 500046 Hyderabad, India, e-mail: m_romesh@yahoo.co.in \& msromesh@gmail.com

AIDS across the world. Since 1985, the percentage of women among adults living with HIV/AIDS has risen from 35\% to $48 \%$. Of particular concern are the dramatic increases in HIV infection among young women, who now make up over $60 \%$ of 15 -to-24-year-olds living with HIV/AIDS. Young women are 1.6 times more likely to be living with HIV/AIDS than young men [1]. The HIV and AIDS pandemic both fuels and is fuelled by inequalities across gender, race, ethnicity, and class. Its effects vary across different settings and regions of the world and are also shaped by armed conflicts, natural disasters, environmental degradation, state incapacities, famine, and poverty. Its refractory impacts on women and girls and humanity writ large are nothing short of catastrophic.

Article history:

Received: 26.07.2016

Received in revised form: 10.10 .2016

Accepted: 01.11.2016

Available online: 18.01.2017
International Journal of HIV-Related Problems

HIV \& AIDS

R e v i e w 
The third decade of the pandemic is characterised by subepidemics that are now coursing through many parts of the globe and among groups previously considered to be unaffected.

Considering this backdrop, the present paper attempted to examine the problems of HIV/AIDS infected women in Manipur and the challenges ahead to capture special attention from various organisations and the concerns of authorities that are working for the empowerment of women in the state.

This paper is based on the reviews from the writings of different scholars and practitioners. The author has attempted to bring out the various problems faced by HIV infected women in Manipur. The HIV and AIDS pandemic both fuels and is fuelled by inequalities across gender, race, ethnicity, and class. Its effects vary across different settings and regions of the world and are also shaped by armed conflicts, natural disasters, environmental degradation, state incapacities, famine, and poverty.

\section{Gender, discrimination, and HIV/AIDS}

The literature addressing the intersections between gender, culture, and HIV tends to focus on specific groups of women or specific practices rather than on how gender organises relational interactions within families, communities, and institutions in everyday life. Problems and risks relating to HIV continue to be assessed mainly in terms of 'vulnerable groups' and 'high-risk behaviours' rather than in relation to the socio-structural and environmental factors that shape individual behaviour and place particular groups at disproportionate risk. While a confluence of factors from poverty and conflict to age and family status are broadly recognised as significant in determining risk behaviours, HIV and AIDS policies and programmes have yet to distinguish adequately among, and adapt specifically to, varied circumstances or key populations.

Gender has been underutilised as an analytical tool. Focusing on the new geography of HIV, they show how globalisation shapes vulnerability to HIV along strongly gendered lines. As O’Manique points out, some of the global economic and social forces that determine HIV risk disproportionately affect Africa, suggesting that the feminisation of the pandemic in sub-Saharan Africa is not so much a product of local biological or social factors as of the ways in which global forces have exacerbated vulnerabilities. It also shows how focused analyses of women's vulnerability may also detract attention from the more insidious and pervasive role of gender. The language of vulnerability and disempowerment, whether deliberately or not, offers up a convenient representation of women as victims. This glosses over the ways in which socio-economic conditions may lead men and women into situations where they are vulnerable [2]. It leaves unaddressed the possibility that behind the metaphor lie very real forms of sexual violence that may be far more widespread and systematic than has been acknowledged. Moreover, the metaphor of woman as victim elides the subtle ways in which male social vulnerability is produced through prevailing masculinities that discourage educational achievement and sanction self-destructive behaviour. It is a metaphor that shuts down thinking and obfuscates difficult but necessary questions about individual agency.

Although the epidemiology of the HIV and AIDS pandemic continues to be explained largely in biomedical and behavioural terms, more attention is now being paid to the social, political, and economic factors that shape individual behaviour and the effectiveness of responses. But even this growing attention is not nearly enough. For young women, mutually reinforcing biological and social vulnerabilities form a particularly toxic combination that is driving a feminisation of the pandemic in some of the hardest-hit countries in the world. We continue to be concerned that the focus of HIV interventions on children in isolation from their social and family context, on prevention technologies, and on celebrity aid may be deflecting attention from broader forms of social and gendered violence that shape HIV risk for both women and men. If the deeply rooted social and cultural norms that increase risks for girls, young women, and other at-risk populations are not understood and taken into account, HIV prevention strategies will continue to be ineffectual as the pandemic unfolds over generations. Addressing the gender dimensions of the pandemic will require a far deeper understanding about how to support families and communities as they negotiate the pandemic's repercussions for household restructuring, gender and intergenerational relations, reproductive decision-making, livelihood choices, education planning, and civic participation [3].

Equally urgent is the need to develop the knowledge necessary for strengthening national response capacities so that those most affected by HIV and AIDS do not also have to shoulder their associated burdens alone. The prevailing institutional logic of international response must be adapted to realities on the ground as experienced by those most affected by HIV and AIDS. And this will require that careful attention also be paid to local voices and regional differences. In addition, we need to study how international interventions are themselves shaping the course of the pandemic and how they interact locally to structure biosocial vulnerability in gendered terms [4].

Gender inequalities increase women's vulnerability to HIV infection, while the HIV epidemic further entrenches gender inequalities. A lens foregrounding exclusionary processes can provide a new understanding of HIV and gender inequalities and thereby suggest new directions for policies and actions. Such a lens reveals the multidimensional and inter-related processes embedded in unequal power relationships that create social, political, cultural, and economic inequalities whilst also highlighting the agency of oppressed individuals and groups. There is urgent need for policy action to address the profound inter-relationship between the epidemic of HIV and deeply embedded gender inequalities. 


\section{Discussion}

India is among the worst affected nations in the world in terms of the HIV/AIDS epidemic. The first case of HIV infection was reported in May 1986 in Madras. The National Institute of Virology, Pune and the Christian Medical College, Vellore started screening operations in 1987 on the recommendation of the AIDS Task Force of the Indian Council of Medical Research, New Delhi. It screened 3027 persons of high-risk groups and detected a good number of cases as being seropositive [5]. Since then HIV infection and AIDS cases have been reported in all parts of the country. The National AIDS Control Organization of India (NACO) reported that the total number of people being HIV positive in India was 5.1 million in 2004. This is second only to South Africa, where the figure is marginally higher. India accounts for almost $10 \%$ of the 40 million people living with HIV globally and over $60 \%$ of the 7.4 million people living with HIV/AIDS in the Asia pacific region. In India, women comprise from one third to one half of the population infected with the HIV virus [6]. Until recently the majority of women having HIV/AIDS and at risk of contracting HIV/ AIDS were categorised as belonging to the vulnerable group of prostitutes and other high-risk groups, but it has become quite clear that it has spread to several groups of the general population, particularly young women between the ages of 14 and 35 years. The HIV infection has spread all across the regions and all groups. Today, it has become not only a public health problem but also one that has a negative impact on the dynamics of the social, cultural, economic, and developmental pace of the society.

However, the growing impact of HIV/AIDS on women has captured serious attention from all walks of life to examine deeply ways in which to combat the poverty and gender inequalities that drive the epidemic. In fact, HIV/ AIDS has exposed the social inequities that make women vulnerable to infection. Physicians and others in health care institutions were slow to recognise women and children at risk. Although female AIDS cases were increasing rapidly in the mid 1980s, these cases were being overlooked [7]. There are a good number of books, articles, and papers based on the problem of HIV victims in the general population across the country, but still we find a lack of studies and write up on this problem especially focused on women.

\section{HIV / AIDS scenario in Manipur}

Manipur, which has an international border of about 350 kilometres with Myanmar, became the victim of international drug smuggling when the notorious traffickers found the route through this point of the international border as a soft route. With national roads leading directly to nations of the "Golden Triangle" of South Asia, the drug trade and drug abuse is widespread especially in India's North Eastern state of Manipur. This is further complicated by the rise in HIV/AIDS among young drug users.

The state has also witnessed an alarming rise of HIV/ AIDS infected persons, which has been the most serious public health problem, and AIDS has become the number one killer of young people. Manipur is also known as the epicentre of AIDS in the North Eastern states. Moreover, this tiny state is one of the top six states, having more HIV-positive cases in the country. Manipur is the first and only state that has a written state AIDS policy in India. In Manipur out of 652,687 blood samples screened up to 2012, the total number of HIV-positive cases is 42,116 , of which 11,778 are women and 2773 are children [8]. It is important to mention that the most important route of transmitting HIV in the state has been the sharing of infected needles among the IDUs (76\%) whereas in other parts of India more than $74.18 \%$ of HIV-positive cases have been through sexual transmission. Quality testing of heroin (brown sugar), indulged by drug traffickers themselves, has to some extent contributed the epidemic as they travelled between Manipur and Myanmar. Besides, commercial sex workers are also vulnerable to HIV and represent a relatively significant core group of transmission of the virus through their clients in the state. The Manipur State AIDS Control Society (MACOS) has identified three areas in which commercial sex workers are working. One is in the centre of Imphal town and the other two areas are in the towns of Churchandpur and Moreh, both are closed to the Burmese border. Such activity is more pronounced in Moreh, where lots of business transactions take place between the two countries [9]. Most of the commercial sex workers working in Moreh come from Myanmar. They come to Moreh in the daytime, carry out their activities in Moreh, and return to their respective homes after finishing business for the day. More than 20\% of commercial sex workers in Moreh are HIV infected. These are girls and women who are often visited by injecting drug users who are HIV positive.

\section{Impact on HIV infected women in Manipur}

It is quite clear that the HIV/AIDS epidemic is not only confined to injecting drug users, as it has spread to their sexual partners, to their children, and to others as well. The majority of infected people belong to younger and working age groups, and it has been reported that the HIV sero-prevalence rate among pregnant women has also raised alarmingly. More than $90 \%$ of the HIV-positive women became infected from their husband. Subsequently, the number of HIV/AIDS affected widows and children has also increased [10]. All of the districts in the state have been affected, where eastern and western districts of Imphal accounted for $68.19 \%$ of the total HIV positive population followed by Thoubal and Churchandpur districts, which accounted for 9.49\% and 5.68\%, respectively. There is no clear reason for having fewer infected persons in one area and higher prevalence in another area. It is recorded that $10-16 \%$ of addicts have history of exposure to commercial sex workers [11]. As result, HIV infection spreads from intravenous drug users to their sexual partners and the population at large. There are many women and children who have acquired the infection 
or face high risk due to unprotected sex behaviour among spouses. Due to this trend, many innocent women and their children have become victims of HIV in Manipur. The HIV prevalence rate among pregnant women is $3.5 \%$ in urban areas, whereas in rural areas it is around $1 \%$. This is slowly and steadily increasing. The recent trend of spreading HIV among women has posed a serious threat and challenge to the wellbeing of society at large.

In India, when one looks at the nature of spreading HIV among women, and from them to others, it is common that the main reasons or factors are commercial sex workers, because IDUs are not common among women. The way that HIV/AIDS is spreading among women and from them to others is slightly different from the rest of the country. For instance, in Manipur society, elders or guardians of IDUs always prefer to look for a girl to get marry with their addicted son so that they can be protected from such bad habits, but fail to do so in the majority of cases. Such practice also contributes to increasing the number of female HIV victims in the state. Despite having higher female literacy in Manipur, people are not coming forward to inculcate a culture of testing the blood of the bride or groom before their marriage, which is a pressing need of the moment to save the precious lives of the many innocent women in the state. Moreover, the culture of the society does not permit people to opt for testing a blood sample before marriage. As a result, many of the innocent girls get married to HIV infected person without knowing.

\section{Awareness level/social stigma, and suffering}

Despite various programmes and intervention activities, it is worth mentioning that the majority of people in rural areas are not fully aware of HIV/AIDS and its associated problems. Moreover, many victims fail to confirm whether they are HIV positive or not. In such cases, many people have died across the state with AIDS but they have not been numbered in official records.

In most of the areas, people living with HIV face discrimination. For instance, they have been rejected by families, spouses, and communities, and they have been refused medical treatment. Such acts from the society also hinder the efforts to prevent new infections. While such strong reactions to HIV and AIDS exist, it is difficult to educate people about how they can avoid infection. Initially, AIDS outreach workers and peer-educators have reported harassment, and in schools, teachers sometimes face negative reactions from the parents of children whom they teach about AIDS. The situation is better in urban areas, but it is worse in the rural areas of Manipur where intervention programs are not reached. Besides, discrimination is also noticed in the health care sector. Negative attitudes from health care staff have generated anxiety and fear among many people living with HIV and AIDS. As a result, many keep their status secret just to maintain a normal life within the community.
It is also generally accepted that India is a male dominated society; the problem for the women is huge. For instance, in Manipur, when both husband and wife are sick, the care shown by the family is never the same. And the problem multiplies when the man passes away, leaving the children behind. The family do not show sympathy towards the woman who became infected through the drug habits of their son. There is already wide discrimination prevailing toward women in the society. It is quite unfortunate that when infected women should be given love, care, sympathy and support, they are instead mistreated and isolated. There are cases where some bed-ridden HIV/AIDS patients are isolated and ill-treated even by their family members [12]. This incidence also clearly shows that the impact of HIV/AIDS is more harshly felt by women, especially in poor families.

It is important to highlight some of the major suffering that is faced by women HIV victims in Manipur. Most of the women who are already affected or are likely to be affected are in the age group of 20 s to late 30 s, and at this stage their sexual urge is very high. Also, the majority of them belong to low-income groups. With their spouses or husbands already dead or completely lost to drugs, they are left with no other option than to come out. It leads to frustration, depression, biological dissatisfaction, and financial problems. In the due course of time, they start looking for easy ways of earning by doing cheap things to fulfil or satisfy their needs. At the same time they also face various constraints from the existing cultural practices of society. Even if they try to start something normal, some way of either earning or fulfilling their needs, they just cannot do it due to cultural boundaries. Naturally, to overcome this dilemma they become a soft target, mainly in the form of sexual exploitation, or they start looking for an easy target, sometimes even re-marriage, extra marital affairs, etc. These can also be considered as the main cause for spreading HIV/AIDS in the state.

There are many cases of female children who have lost their parents due to HIV/AIDS. They have a tough time coping with studies in school as well as their local surroundings. Their social circle is confined to people who are living in similar circumstances. Also, it may not be out of place to mention that many of the HIV/AIDS widows continue to have sexual relationships with their dead husbands' friends and relatives to win sympathy and find social acceptance. This also contributes to the spread of HIV in the state since condom culture is not popular. In general, women in any case tend to be negligent of health issues; with widows the reluctance to access health services is even higher. As mentioned above, promoting condom use among males is not an easy task because women or widows do not dare to instruct their partners to use a condom to have protected sex, given they are already vulnerable and in a marginalised situation.

Most of the infected women are in the reproductive age group. HIV/AIDS among women has been increasing at a fast pace. There were cases where many women were shocked and fainted after discovering their positive status. 
It has created a big emotional threat to women in particular and society in general.

The harsh reality of being a widow in our society is that if the dead husband happens to be an HIV-positive man and died of AIDS then the widow surely experiences dual stigmatisation - first as a widow and second as a widow of an HIV-positive man. In the later stage there is every possibility of transmitting the disease to the child if a woman bears a child in her womb. There is no cure for HIV/AIDS and it is still one of the greatest challenges to medical science of our time. This ultimately forces people in the state to look at these HIV-positive men, women, and children differently and treat them very badly in various social spheres.

Hence, the impact of HIV is also more severely felt by women in poor families. In these families, women provide financial support to the family and they find it difficult to earn their livelihood due to poor availability of work in the state. In such a situation, they are often forced to work as commercial sex workers. This has also increased the risk of infection among women who were previously considered as being in a low-risk group. One should be aware that risk of infection among women means the risk of infection for generations to come.

\section{Government and NGO intervention}

There are various national and international agencies like the National AIDS Control Program (NACO), being a major source of finance, and the UNDCP, UNAIDS, OXFAM, and SIDA have been working in the field, supporting various NGOs. Moreover, the Manipur AIDS Control Society (MACS) shoulders the sole responsibility of receiving and disbursing funds from NACO. The Government and NGOs have been implementing programs and project activities in the form of intervention (counselling, condom promotion, medical check-up, needle and syringe exchange programs) among vulnerable groups [13]. However, much of the existing intervention and prevention programs in Manipur have focused on IDUs while there is a scarcity of services or programs that are in tune with the basic needs of women who are infected with HIV/AIDS. In the purview of existing programs, women do not have the courage to come out openly because HIV/AIDS is often associated with one's morals, social stigma, and discrimination. Moreover, the existing gender equity in the state, lack of knowledge and negotiating power with their partner or family member, and lack of financial independence restricts them to avail various interventions, prevention programs, and other health-related services facilitated by government and NGOs in the state.

Special attention is paid to the situation in Manipur, where the epidemic - driven by injecting drug use - has been in existence for more than a decade and is spreading to the general population as well. Reporting that the HIV prevalence measured in antenatal clinics in Imphal and Churachandpur in Manipur has risen from below 1\% to over 5\%, the update adds that several factors are likely to sustain it: the large proportion of female sex workers who inject drugs and the relative youth of the injecting drug users [14]. In general, the scarcity of information on women's status reflects the bias of state priorities in the collection and use of data for state programs of development. Pertinent dimensions of women's lives tend to be excluded, underreported, or underestimated as parameters, e.g. information on health status, family life, income activities, etc.

Overall information about the women's health status is not brought out clearly by the concerned authority. They have constantly failed to initiate research studies or surveys over the years to capture the holistic understanding of health problems of women in the state. As a result, there is no proper reliable source of data that can be used to highlight the general health problems of the women. There is a need to develop more appropriate indicators of women's health, and to give higher priority to the collection of sex-specific statistics, especially in areas where the problems are greatest.

\section{Loopholes in HIV/AIDS programs and future challenges}

First and foremost, a major gap area in the various AIDS intervention programmes being implemented in the state is that the National AIDS Control Organisation (NACO) guidelines do not allow the MSACS to undertake any direct intervention programme for AIDS widows and orphans such as building orphanages or shelter homes. Hence, the AIDS widows and orphans continue to be deprived of the benefits of the programmes being implemented either by the MSACS or by NGOs. It is also reported that Manipur AIDS control society has been repeatedly hauled up by the state auditors for diverting vital AIDS funds to other health programs. There are about 100 AIDS NGOs in the state. No doubt, there are NGOS doing good jobs. At the same time, they also face problems relating to accommodation, funding, and manpower. There are complaints about insufficient funding, erratic release of funds, and lack of public support, among others. For better results, such NGOs need to be strengthened with sufficient and timely funding. Side by side their activities should be closely monitored and the non-performing NGOs should be identified and their funding stopped.

There has been a duplication of the intervention programmes/harm reduction strategies in the state by various agencies. There have been many instances in which programmes have been suspended for some time or abandoned altogether due to lack of funds, which does not bode well for people who are living with HIV/AIDS. In the long run, funding agencies will move on to other areas of development work. This means there is an urgent need for community funding and local sustenance for HIV/AIDS interventions.

The overall prevention service of the state is relatively poor, and patients are not getting the opportunity to access general health services. As a result, people find it difficult to detect epidemics. Besides, concerned authorities are not efficient enough to handle the diagnosed HIV/AIDS cases due to non-availability of specially trained medical personnel. The existence of various armed groups resorting to guerrilla 
warfare against the various central and state security forces that are deployed in huge numbers to maintain peace and order have only contributed to the complexity of the situation.

\section{Conclusions}

Recapitulation of the above discussion shows that combating HIV/AIDS in Manipur has a long way to prove its worthiness to society, despite huge expenditure on preventing the epidemic. Lack of trained people, mismanagement of funds, unrest problems, and the fact that the help is confined to urban areas and neglects rural people and women are also contributing to the failure of the programs. There is no research support to the programme. Therefore, the government should initiate research and evaluation studies phase by phase to understand the current situation of the epidemic and the problems associated with the various intervention programs. This exercise will certainly help us to get firsthand information about the basic needs of HIV infected people and their problems. Flexible strategies that are in tune with their requirements can be planned for future intervention programs.

There should be transparency in fund management and streamlining of the administrative system; there is a need to expand coverage, especially in rural areas, by establishing more counselling centres and camps, separate packages for women, and immediate intervention strategies to prevent the further spread of infections among women. Above all, HIV/AIDS intervention programmes should be in-tune with the socio-cultural-economic conditions of the concerned areas. Finally, rehabilitation and training programs on stress management skills, and survival skills of recovering drug users and people with HIV/AIDS has to be implemented effectively along with employment-oriented programmes by collaborating with other development departments to provide sustainable livelihood to HIV affected people in the state.

On the other hand, the state has failed to notice the fast spread of HIV among women and children. Hence, there is an urgent need to pay special attention to the control the transmission of HIV/AIDS from mother to child. Otherwise, it will become a major stumbling block to the future prosperity of society. It is universally accepted that women and children are the basis of a society, children are considered as pillars of the society, and it is impossible to make a progressive society without empowering women and children in the state. However, government and NGOs have been implementing many strategies and awareness programmes for controlling HIV/AIDS and give much attention to the general population of the state. Unfortunately, there is no specific strategies or programmes that provide special packages for confronting HIV/AIDS among women and children. Considering this fact, concerned authority should pay serious attention to implementing a complete separate strategy for women and children because their life is precious for building a harmonious and prosperous society. They also required extra care and special attention to overcome their unwillingness to reach various HIV/AIDS programmes due to social stigma, personal hesitation, and many other constraints as a woman. It is also important that HIV/AIDS policies are properly designed bearing in mind the socio-cultural flexibility of the society.

\section{Conflict of interest}

The author declares no potential conflicts of interest with respect to the research, authorship, and/or publication of this article.

\section{References}

1. UNAIDS (Joint United Nations Programme on HIV/AIDS), Report on the Global AIDS Epidemic. Geneva, UNAIDS, 2008; 1-357.

2. O'Manique C. Neoliberalism and AIDS Crisis in Sub-Saharan Africa: Globalization's Pandemic. Basingstoke, United Kingdom, Palgrave Macmillan, 2007; 1-198.

3. Baylies C, Burja J. The Struggle Continues: Some Conclusions. In: AIDS, Sexuality and Gender in Africa. Baylies C, Burja J (eds.). Routledge, London 2000; 175-198.

4. Hunter M. The changing political economy of sex in South Africa: the significance of unemployment and inequality to the scale of the AIDS pandemic. Soc Sci Med 2007; 64: 689-700.

5. Talukdar S. Fighting AIDS in Manipur. The Hindu, Chennai, August $16,2005$.

6. Narain JP. AIDS in Asia: challenge ahead. Sage Publications, New Delhi 2004.

7. Barnett T, Whiteside A. AIDS in the Twenty-First Century: Disease and Globalization. Palgrave MacMillan, Basingstoke 2002; 159-198.

8. Manitombi K. AIDS and Women's Crux in India (Manipur). Voice of Research 2013; 2: 6-10.

9. National AIDS Control Program, Manipur, 2001-2002, Manipur AIDS Control Society (Status Report), Imphal, 2001-2002; 120.

10. AIDS Alerts, Manipur AIDS Control Society, 2001; 3: 1-4.

11. National AIDS Control Program, Manipur AIDS Control Society (Status Report), Imphal, 2004-2005; 132.

12. Samarendra M. Tribute to AIDS Victims. Imphal Correspondence, E Pao 2005.

13. Irengbam R. HIV/AIDS in Manipur. J Health Develop 2005; 1: 15-23.

14. Ahanthem Ch. Manipur: Fighting Against HIV/AIDS; www://oneindiaonepeople.com, 2004. 